Квон Д.

\title{
Основные особенности и проблемы театрального образования в Корее
}

\begin{abstract}
Аннотация: Предметом исследования в данной статье является театральное образование в Корее и его проблемы. Наибольшей проблемой современного корейского театра являются взаимоотношения между актером и режиссером, которые продолжают жить на сцене, опираясь на традиционные конфуцианские традции поведения. Актеры для современного корейского театра готовятся в университетах, однако корейская система высшего театрального образования до сих пор находится в процессе становления. За исключением некоторых университетов, в Корее нет разделения на актерский, режиссерский и театроведческий факультеты, а есть только театральные или кино-театральные факультеты. В исследовании используется сравнительный метод, когда система театрального образования в Корее сравнивается с российской системой, основанной на методе Станиславского. Основным выводом приведенного исследования является утверждение о том, что дополнение уже привычной корейцам системы Станиславского методом Мейерхольда сможет способствовать формированию национального театра, так как условность, присущая этому методу является основой национального театра Кореи. Обогащение метода К.С. Станиславского педагогическими приемами В.Э. Мейерхольда может быть полезным для корейской актерской школы и оказаться тем путем, которым корейский студент может пройти в театральный мир.
\end{abstract}

Ключевъе слова: Театральное образование, корейский театр, конфуцианство, актер, режиссер, корейцы, система Станиславского, Мейерхольд, корейский менталитет, профессиональный театр.

Review: The subject of the present research article is the theatre education in Korea and associated problems. The biggest problem of the modern Korean theatre is the relationship between actors and directors based on traditional Confucianism and traditional patterns of behavior. Even though contemporary Korean actors receive their education at universities, Korean system of higher theatre education is still in the process of development. Except for some universities, most Korean universities do not have individual departments of acting, stage directing or theatre history but have only general drama or cinematographical-theatrical faculties. The researcher has used the comparative method to compare the Korean system of theatre education with the Russian system of theatre education based on Stanislavsky's method. The main conclusion of the research is that Stanislavsky's system Koreans are already accustomed to should be completed with Meyerhold's method which may contribute to the development of the national theatre because conditionality is the main feature of Meyerhold's method and the basis of the Korean national theatre. Enrichment of Stanislavsky's method with Meyerhold's pedagogical techniques can be useful for the Korean acting school and provide the key to success of a Korean student in the theatre world.

Keywords: Professional theatre, Korean's mentality, Meyerhold, Stanislavsky's system, Koreans, director, actor, Confucianism, Korean theatre, theatre education.

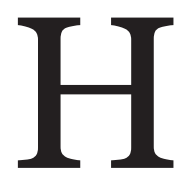

овая драма и театр европейского образца появились в Корее только в первой трети XX века, а расцвет его начался лишь в 1980-е годы. В последнее время большинство корейских спекткалей ставится на основе реализма, то есть корейский театр испытывает сильное влияние системы Станиславского, которая появилась в Корее через японские переводы c английского. Уже почти 100 лет корейский театр приобщается к европейскому театральному искусству, используя европейские актерские методы и системы.

Наибольшей проблемой современного корейского театра являются взаимоотношения между актером и режиссером, которые продолжают жить на сцене, опираясь на традиционные конфуцианские традции поведения. Актеры для современного корейского театра готовятся в университетах, однако корейская 
система высшего театрального образования до сих пор находится в процессе становления.

В 1953 году был открыт первый Институт искусств (Сораполь), хотя до этого момента театральное образование можно было получить только в труппе. Сейчас в Сеуле, столице Кореи, насчитывается 290 театральных трупп[15, 65], однако длительного систематического актерского образования в труппах почти нет. Только в Театральной ассоциации для уже состоявшихся актеров проводятся краткосрочные курсы повышения квалификации актеров (занятия проводятся 1 раз в неделю в течение семестра). Или же одна из трупп проводит однократные семинары по мастерству актера.

В 1970-х года в Корее произошел довольно резкий экономический подъем, вырос уровень жизни, и искусство стало занимать важное положение в обществе. С конца 1990-х годов с большой скоростью стали открываться театральные факультеты в высших учебных заведениях. В связи с этим театральное образование из трупп перешло в университеты и институты.

Обучение в институте и университете отличается тем, что в университете учатся 4 года, а в институте - 3. Сейчас в Корее 79 университетов имеют театральные факультеты [14, 124]. Причиной такого необычайно быстрого развития высшего театрального образования стало желание большого количества молодых людей посвятить свою жизнь творческой сфере, а вернее сказать - стать звездами экрана. В настоящее время большинство популярных кино- и телевизионных актеров закончили театральные факультеты.

Отказ театральных трупп от театрального образования имеет несколько причин, главная из которых состоит в быстром развитии театральных факультетов университетов.

Несмотря на то, что за последние сто лет театральное мастерство корейских актеров и режиссеров значительно возросло, а театральное образование перешло из народной среды в высшие учебные заведения, в театральном искусстве все еще есть довольно значительные проблемы, которые мы не можем обойти вниманием в настоящей работе.

На театральных факультетах, как правило, от студента требуется овладение определенными умениями, навыками и знаниями в определенный срок. При этом образовательный процесс довольно специфичен: получаемые знания не глубоки, а скорее уни- версальны. Универсальность получаемых знаний восходит к синтетичности театрального искусства и искусства вообще. Однако универсальность образовательного процесса исключает географические, общественные, временные, культурные особенности, раскрывая только минимальное содержание театрального образования.

Методика обучения в корейских театральных вузах сильно отличается принятой в России системы. Например, в ведущих московских театральных вузах разделены актерский и режиссерский факультеты, а в случае ГИТИСа имеются также факультеты эстрадного искусства, театроведения, сценографии и т.д. На каждом факультете в зависимости от его специфики студенты получают специальное образование. В Корее же, за исключением некоторых университетов, нет разделения на актерский, режиссерский и театроведческий факультеты, а есть только театральные или кино-театральные факультеты в общем.

На кино-театральных факультетах на начальном этапе обучения также нет разделения на кино и театральные группы, поэтому студенты слушают лекции по обоим направлениям. На самом же деле мастерство кино и театральное мастерство сильно различаются, и для тех, кто имеет цель стать театральным актером, подобная образовательная система не предоставляет достаточного количества занятий по актерскому мастерству, а значит у студента остается мало шансов получить хорошее, глубокое специальное образование.

В России студенты учатся под руководством одного мастера и одной и той же группы педагогов в течение всего периода обучения (4 года), за который студенты постепенно проходят путь от азов (этюдов и отрывков из пьес) к постановке спектакля. В Корее же профессор меняется каждый семестр, поэтому системность образования складывается с трудом. Кроме того, в корейской театральной школе отсутствует общепринятая терминология. Как замечает в своей диссертации Ким Чжун И, «в программах театральных вузов Кореи вообще отсутствует система воспитания актеров, в ней нет логики и необходимой последовательности» $[8,3]$.

При этом большинство профессоров театральных факультетов Кореи как правило специализировались на литературе или теории театра, а не на режиссерском или актерском мастерстве. Конечно, для театрального образования гуманитарные науки необходи- 
мы, но большинство студентов, поступивших на театральный факультет, хочет быть актерами, поэтому в процессе образования необходимо основной упор делать на практику.

Однако именно практики в театральном образовании Кореи недостает. Практические предметы часто преподаются посторонними, приглашенными преподавателями. Каждый из приглашенных педагогов пользуется своим методом, что в общем неплохо для студентов, но с другой стороны, студенты находятся в смятении от многообразия педагогических систем и методов преподавания. В результате, такая ситуация в театральном образовании становится проблемной как для профессоров, так и для студентов, так как профессора каждый семестр должны преподавать большое количество предметов, которые студенты не всегда готовы полностью воспринять и чувствуют напряжение и усталость. В связи с этим лишь некоторое количество бывших студентов продолжают актерскую карьеру.

Более всего Корейское и Российское театральное образование отличаются тем, что в корейском театральном образовании гораздо меньше времени дается для того, чтобы разобраться в человеческой индивидуальной органике, в то время как система Станиславского основывается на том, что актер должен в первую очередь хорошо знать себя как личность. Так, в России на первом курсе театрального факультета на занятиях по актерскому мастерству много времени посвящается этюдам на органическое молчание, а также наблюдениям за животными и людьми, в Корее же с первого курса студентам приходится работать с авторским словом. В Российском театральном образовании студент сначала узнает возможности собственной органики, учится работать с предлагаемыми обстоятельствами и действовать в своей природе чувств, не надрывая ее в погоне за результатом. В Корее в принципе выделяется меньше часов на актерское мастерство, поэтому корейских студентов на занятиях по актерскому мастерству учат не столько мастерству, сколько псевдо-технике актера.

Проблемам корейских актеров и вопросам обучения в корейских театральных вузах были посвящены две диссертации, защищенные в РАТИ-ГИТИС в 2010 - 2011 годах: Ким Чжун И «Особенности обучения корейских актеров в русской театральной школе» и Пак Се Хиун «Система Станиславского в обучении корейского актера».
В своих работах исследователи касаются причин возникновения проблем у корейских актеров на сцене. Так, Пак Се Хиун отмечает: «Проблемы игры корейских актеров заключаются в отсутствии сквозного мышления, гипертрофированном проявлении чувств и эмоций, отсутствии процесса рационального мышления, отсутствии действия, искусственности, преувеличенности, инфантильности, подавленности, приблизительности, преобладании техники, недостатке реалистичности в исполнении и т.д. Режиссерские же проблемы заключаются в отсутствии понимания событий, абстрактности, отсутствии логики, недостатке фантазии, отсутствии осознания того, что надо воспитывать актера и т.д.»[11, 5]. Причину этих проблем исследователь видит в отсутствии осознания себя на сцене, то есть отсутствии субъекта.

Основные причины этих проблем, по мнению Пак Се Хиун кроются в традиционной «семейственности» корейцев, восходящей к традиционному конфуцианскому мировоззрению.

В Корее до сих пор сильна конфуцианская идеология, и традиционные семейные ценности, поддерживаемые ей, чрезвычайно важны для корейца. Семья считается идеальной структурой, и независимость отдельных ее членов оказывается менее важным фактором, чем интересы всей семьи целиком. Пак Се Хиун называет такую ситуацию «семейственностью». Семейственность распространяется на все корейское общество в целом. Подобные семейные принципы оказываются важным фактором в определении социального характера корейца и социальной структуры Кореи. Семья вторгается в личную сферу человека и оказывает большое влияние на формирование индивидуального «я».

Конфуцианство придает главе семейства отцу - сакральный характер, вследствие чего устанавливается патриархальный порядок в семье, который определяет и социально-политическое устройство общества.

Пак Се Хиун подчеркивает, что «дети как члены семьи не могут самостоятельно принимать важные решения, самостоятельно разрешать стоящие перед ними насущные проблемы, их намерения не имеют определяющего значения - они должны следовать решениям старших в семье, поэтому в итоге возрастает эмоциональная привязанность к семье. Вследствие этого они не могут активно участвовать во встречающихся на их пути конфликтах и 
происходящих с ними многочисленных событиях, они остаются пассивными» $[11,12]$.

Таким образом, в Корее, которая издавна зовется «Восточной страной этикета», с детства прививаются необходимые этические принципы, развивающие внешнюю культуру поведения, где в первую очередь приветствуется забота не столько о себе, сколько о других - чон. В результате слишком большие старания в соблюдении этикета ведут к закрытию индивидуальности.

Подобный тип человеческих отношений имеет продолжение и в театральной практике, создавая большие или меньшие трудности для свободного поведения актера на сцене, так как актеры постоянно стараются подстраиваться под партнера, уступая и подчиняя ему собственные действия. В результате действия становятся робкими и мелкими, а конфликт стирается.

Кроме того, патриархальность сильно влияет на взаимоотношения между актером и режиссером. Так, если режиссер старше актеров, то они испытывают к нему большое почтение, вследствие чего не могут вступать с ним в диалог, потому что корейский этикет не предусматривает возможности диалога между более молодым актером и старшим режиссером. И для того, и для другого участника диалога подобное поведение находится за рамками установленного этикета, и особенно такое положение усугубляется при наличии посторонних взглядов. И наоборот, если режиссер младше актера, то ему становится очень трудно донести собственный замысел до актеров. При этом большинство актеров осознает, что соблюдение подобных норм вредит театральному творчеству, однако никто не решается открыто игнорировать устоявшиеся традиции.

Корейский менталитет, обусловленный конфуцианскими традициями и воспитанием, проявляется также и в образовательном процессе, когда студенты встречаются с проблемой неизвестной, или плохо понимаемой. Стесняясь задать вопрос педагогу, то есть, чувствуя стыд за собственное невежество, студенты просто проходят мимо проблемы, боясь быть бестактными. Отношения между педагогом и студентами обладают жесткой вертикальной структурой, и человек, который во время занятий задает вопросы о том, чего он не знает или не понимает, воспринимается как человек, делающий глупость. Кроме того, обучение в начальной, средней и полной средней школе в Корее не предусматривает непосредственного участия учеников в дискуссиях с педагогами. В результате у учащихся не вырабатывается навыка свободного ведения диалога, они не могут отстаивать собственные убеждения и делиться собственными размышлениями. Они не умеют общаться с педагогами, и зачастую боятся этого, замыкаясь в себе. Естественно, такая система образования не способствует развитию личного нестандартного мышления.

Таким образом, проблемы, связанные с традиционным конфуцианским воспитанием переходят и на образование, где еще более усугубляются. Кроме того, современный молодой человек в Корее находится в сложном и противоречивом влиянии на него европейской культуры, идей глобализма и других современных противоречий, которые трудно объяснить некорейцу.

Все вышеназванные проблемы проявляются на сцене корейского театра в том, что актеры как будто стыдятся своих внешних проявлений во время происходящих с ними событий, поэтому и на сцене они не реагируют на события с должной активностью.

Можно с уверенностью утверждать, что наибольшей проблемой современного корейского театра являются профессиональные взаимоотношения актера и режиссера, которые опираются на традиционные конфуцианские традиции поведения и в репетиционном процессе, и в манере жить на сцене.

Эти особенности национального менталитета необходимо учитывать при воспитании современного корейского актера, особенно если обучение проводится по европейским методикам.

Корейские театральные институты, в основном, используют систему Станиславского при воспитании актера. Однако подробный психологический анализ, лежащий в основании разработанной великим режиссером работы актера над ролью, противоречит, с одной стороны, особенностям эмоционального мира корейцев, а с другой, далек от корневых традиций народного театра с его масочностью и символичностью.

При этом ближе к устройству личности корейского актера некоторые базовые особенности сценической педагогики В. Э. Мейерхольда: внимание к «фиксации» пластического и интонационного рисунка роли, «знаковый» характер актерской пластики, стремление к точному внешнему оформлению внутреннего, душевного содержания образа. Такие приемы актерского мастерства в 
большей мере соответствуют эмоциональной природе корейского актера.

С нашей точки зрения, обогащение метода К. С. Станиславского педагогическими приемами В. Э. Мейерхольда может быть полезным для корейской актерской школы и оказаться тем путем, которым корейский студент может пройти в театральный мир. Кроме того, в процессе формирования национальной актерской школы нельзя не учитывать и свойственные народной театральной культуре традиции передачи профессионального мастерства «из рук в руки», основанной на традиционных национальных ценностях. Их тоже необходимо использовать, включить в процесс преподавания в качестве органической части, дополнительной по отношению к первым двум.
Такой обощенный подход будет близок менталитету корейца, так как он позволит не полностью открывать душу, раскрывая сокровенное, а в обобщенно-поэтической форме заниматься конкретными элементами психотехники, которые и смогут передать это сокровенное через символическую дистанцированную форму. Таким образом, студент может сохранять некоторую «целомудренную» дистанцию между собой и педагогом или режиссером, что создаст им обоим больше комфорта.

На наш взгляд, дополнение уже привычной корейцам системы Станиславского методом Мейерхольда сможет способствовать формированию национального театра, так как условность, присущая этому методу является основой национального театра Кореи.

\section{Библиография:}

1. Мейерхольд В.Э. Статьи. Письма. Речи. Беседы: в двух частях. Часть первая (1891-1917) / В.Э. Мейерхольд; сост., ред., комм. А.В. Февральский; ред. Б.И. Ростоцкий. М.: Искусство, 1968. 360 с.

2. Марков П.А. Письмо о Мейерхольде // Марков, П.А. О театре: в 4 т. Т. 2: Театральные портреты / П.А. Марков. М.: Искусство, 1974. С. 59-75.

3. Рудницкий К.Л. Режиссер Мейерхольд / К.Л. Рудницкий. М.: Наука, 1969. 527 с.

4. Войновская Д.Н. Актер в театре В.Э. Мейерхольда. Формирование педагогических принципов В.Э. Мейерхольда в условиях эволюции его режиссерского метода: 1902-1917 гг.: автореф. дисс. ... на соиск. уч. степ. канд. искусствоведения: специальность 17.00.01 - театральное искусство [Электронный ресурс] / Д.Н. Войновская. М., 2012. - URL: http://www.gitis.net/rus/postgraduate/notices/v/voynovskaya_auto.shtml (дата обращения: 15 сентября 2015 года)

5. Песочинский Н.В. Проблемы актерского искусства в театральной концепции В.Э. Мейерхольда (1920-1930 годы): дисс. ... канд. искусствоведения: специальность 17.00.01 - театральное искусство [Электронный ресурс]. Л., 1983. 227 с. // Сайт «Сайт «disserCat». - URL: http://www.dissercat.com/content/problemy-akterskogoiskusstva-v-teatralnoi-kontseptsii-v-e-meierkholda-1920-1930-gody (дата обращения: 23 августа 2015 года).

6. З Захава Б.Е. Мастерство актера и режиссера / Б.Е. Захава. 2-е изд., испр. и доп. М.: Искусство, 1969.319 с.

7. Создание актерского образа. Теоретические основы / Сост. и отв. редакторы Н.А. Зверева, Д.Г. Ливнев. М.: РАТИ-ГИТИС, 2008. 224 с.

8. Ким Чжун И. Особенности обучения корейских актеров в русской театральной школе: дис. соиск. уч. степ. канд. искусствоведения: специальность 17.00.01 - театральное искусство. М., 2010. 133 с.

9. О Сун Хан. Значение русской театральной школы для воспитания современного актера в Корее (синтез методики: К.С. Станиславский, Вл.И. Немирович-Данченко, М.А. Чехов): дис. ... канд. искусствоведения: специальность 17.00.01 - театральное искусство. М., 2005. 145 с.

10. О Чжин Хо. История развития корейского театра в свете освоения системы Станиславского: дис. ... искусствоведения: специальность 17.00.01 - театральное искусство. М., 2005. 146 с.

11. Пак Се Хиун. Система Станиславского в обучении корейского актера: дис. ... канд. искусствоведения: специальность 17.00.01 - театральное искусство. М., 2011.120 с.

12. Ха Сун Чжу. Пути обогащения корейской театральной педагогики методом и приемами русской театральной школы: дис. ... канд. искусствоведения: специальность 17.00.01 - театральное искусство. М., 2005. 156 с.

13. Чой Ю Ри. Этюдный метод в театральном образовании и создании спектакля в Южной Корее: дис. ... канд. искусствоведения: специальность 17.00.01 - театральное искусство. М., 2012. 131 с.

14. Итоги культуры и искусства 2007 года. Сеул: Государственный отдел культуры и туризма, 2008.(на корейском языке).

15. Корейский театр. Сеул: Корейская театральная ассоциация. Декабрь, 2012.(на корейском языке). 


\section{References (transliterated):}

1. Meierkhol'd V.E. Stat'i. Pis'ma. Rechi. Besedy: v dvukh chastyakh. Chast' pervaya (1891-1917) / V.E. Meierkhol'd; sost., red., komm. A.V. Fevral'skii; red. B.I. Rostotskii. M.: Iskusstvo, 1968. 360 s.

2. Markov P.A. Pis'mo o Meierkhol'de // Markov, P.A. O teatre: v 4 t. T. 2: Teatral'nye portrety / P.A. Markov. M.: Iskusstvo, 1974. S. 59-75.

3. Rudnitskii K.L. Rezhisser Meierkhol'd / K.L. Rudnitskii. M.: Nauka, 1969. 527 s.

4. Voinovskaya D.N.Akter v teatre V.E. Meierkhol'da. Formirovanie pedagogicheskikh printsipov V.E. Meierkhol'da v usloviyakh evolyutsii ego rezhisserskogo metoda: 1902-1917 gg.: avtoref. diss. ... na soisk. uch. step. kand. iskusstvovedeniya: spetsial'nost' 17.00.01 - teatral'noe iskusstvo [Elektronnyi resurs] / D.N. Voinovskaya. M., 2012. - URL: http://www.gitis.net/rus/postgraduate/notices/v/voynovskaya_auto.shtml (data obrashcheniya: 15 sentyabrya 2015 goda)

5. Pesochinskii N.V. Problemy akterskogo iskusstva v teatral'noi kontseptsii V.E. Meierkhol'da (1920-1930 gody): diss. ... kand. iskusstvovedeniya: spetsial'nost' 17.00.01 - teatral'noe iskusstvo [Elektronnyi resurs]. L., 1983. 227 s. // Sait «Sait «disserCat». - URL: http://www.dissercat.com/content/problemy-akterskogo-iskusstva-vteatralnoi-kontseptsii-v-e-meierkholda-1920-1930-gody (data obrashcheniya: 23 avgusta 2015 goda).

6. Zakhava B.E. Masterstvo aktera i rezhissera / B.E. Zakhava. 2-e izd., ispr. i dop. M.: Iskusstvo, 1969. 319 s.

7. Sozdanie akterskogo obraza. Teoreticheskie osnovy / Sost. i otv. redaktory N.A. Zvereva, D.G. Livnev. M.: RATI-GITIS, 2008. 224 s.

8. Kim Chzhun I. Osobennosti obucheniya koreiskikh akterov v russkoi teatral'noi shkole: dis. soisk. uch. step. kand. iskusstvovedeniya: spetsial'nost' 17.00.01 - teatral'noe iskusstvo. M., 2010. $133 \mathrm{~s}$.

9. O Sun Khan. Znachenie russkoi teatral'noi shkoly dlya vospitaniya sovremennogo aktera v Koree (sintez metodiki: K.S. Stanislavskii, Vl.I. Nemirovich-Danchenko, M.A. Chekhov): dis. ... kand. iskusstvovedeniya: spetsial'nost' 17.00.01 - teatral'noe iskusstvo. M., 2005. $145 \mathrm{~s}$.

10. O Chzhin Kho. Istoriya razvitiya koreiskogo teatra v svete osvoeniya sistemy Stanislavskogo: dis. ... iskusstvovedeniya: spetsial'nost' 17.00.01 - teatral'noe iskusstvo. M., 2005. 146 s.

11. Pak Se Khiun. Sistema Stanislavskogo v obuchenii koreiskogo aktera: dis. ... kand. iskusstvovedeniya: spetsial'nost' 17.00.01 - teatral'noe iskusstvo. M., 2011.120 s.

12. Kha Sun Chzhu. Puti obogashcheniya koreiskoi teatral'noi pedagogiki metodom i priemami russkoi teatral'noi shkoly: dis. ... kand. iskusstvovedeniya: spetsial'nost' 17.00.01 - teatral'noe iskusstvo. M., 2005. $156 \mathrm{s.}$

13. Choi Yu Ri. Etyudnyi metod v teatral'nom obrazovanii i sozdanii spektaklya v Yuzhnoi Koree: dis. ... kand. iskusstvovedeniya: spetsial'nost' 17.00.01 - teatral'noe iskusstvo. M., 2012. $131 \mathrm{~s}$.

14. Itogi kul'tury i iskusstva 2007 goda. Seul: Gosudarstvennyi otdel kul'tury i turizma, 2008.(na koreiskom yazyke).

15. Koreiskii teatr. Seul: Koreiskaya teatral'naya assotsiatsiya. Dekabr', 2012.(na koreiskom yazyke). 